\title{
¿Blogerización de la medicina? Informalidad académica
}

\section{Blogging of medicine? Academic informality}

\author{
José L. Sandoval-Gutiérrez*
}

Servicios Auxiliares y Paramédicos, Instituto Nacional de Enfermedades Respiratorias Ismael Cosío Villegas, Ciudad de México, México

Gorordo-Delsol y Uribe-Moya ${ }^{1}$ han emitido una comunicación interesante sobre la sinergia entre revistas científicas y blogs académicos. Dentro del cuadro comparativo manifiestan, en el ítem de revisión por pares, que los blogs cuentan con este instrumento en una minoría; lo mismo se entiende por el ambiente de informalidad y discusión que se busca.

Con la pandemia de COVID-19 han proliferado las comunicaciones poco ortodoxas por la imperiosa necesidad de información ágil, pero el problema ha sido la veracidad y la reproducibilidad de los datos. Las opiniones científicas son importantes en cualquier escenario, pero es relevante que el nuevo estudiante de medicina no las confunda, ya que una comunicación científica no tiene el mismo rigor académico si se emite en un libro, una revista, un blog o una red social (Facebook 0 Twitter).

A fin de cuentas, la «prueba del tiempo» pondrá las cartas en su respectivo lugar, como se menciona al final del mencionado artículo, para el beneficio de los profesionales de la salud y los pacientes.

\section{Financiamiento}

El autor declara no haber recibido financiamiento para esta carta.

\section{Conflicto de intereses}

El autor declara no tener ningún conflicto de intereses.

\section{Responsabilidades éticas}

Protección de personas y animales. El autor declara que para esta investigación no se han realizado experimentos en seres humanos ni en animales.

Confidencialidad de los datos. El autor declaran que ha seguido los protocolos de su centro de trabajo sobre la publicación de datos de pacientes.

Derecho a la privacidad y consentimiento informado. El autor declara que en este artículo no aparecen datos de pacientes.

\section{Bibliografía}

1. Gorordo-Delsol LA, Uribe-Moya SE. Revistas científicas y blogs académicos: Ia sinergia perfecta. Rev Educ Investig Emer. 2021;3:159-61.

\section{Correspondencia:}

*José L. Sandoval-Gutiérrez

E-mail: sandovalgutierrez@gmail.com
Fecha de recepción: 06-12-2021

Fecha de aceptación: 10-01-2022 DOI: 10.24875/REIE.21000279
Disponible en internet: 14-02-2022 Rev Educ Investig Emer. 2022;4(1):55-55 www.medicinadeemergencias.com

作 bajo la licencia CC BY-NC-ND (http://creativecommons.org/licenses/by-nc-nd/4.0/). 